\title{
Remembering and Exhibiting Games Past: The Popular Memory Archive
}

\section{Helen Stuckey, Melanie Swalwell, Angela Ndalianis \& Denise de Vries}

\section{ABSTRACT}

The Popular Memory Archive is an online collaborative research portal for collecting and exhibiting the production and reception histories of Australian and New Zealand micro-computer games of the 1980s. Proposed as a resource for both historians of technology and media, and the public, the site provides the means to collect and share the memories of those who lived and played their way through this period. This article surveys activity on the site and offers some preliminary evaluation of the significance of the online contributions. From this we consider the discursive, inclusive and questioning practices of the portal as a means of exhibiting historic games.

\section{Keywords}

Game History, Digital Heritage, Games Preservation, Videogames, Museums, Curation, Fan Culture, Online Communities

\section{Introduction}

Play It Again is a game history and preservation project focused on locally-written digital games in 1980s Australia and New Zealand. It is a collaborative project with the Australian Centre for the Moving Image (ACMI), Ngā Taonga Sound \& Vision (formerly the New Zealand Film Archive) and the Berlin Computerspiele Museum. In October 2013, we launched the Popular Memory Archive, an online collaborative research portal. The portal provides a way to disseminate some of the team's research, but importantly, it also provides a mechanism for collecting information, resources and 
memories from the public about 1980s' computer games. The Popular Memory Archive begins from the premise that in the 1980s games were often the first point of contact with microcomputers, and that in researching the reception of 1980s digital games, the memories of players are key. The ambitions of the Popular Memory Archive are to build resources for historians of technology and media, as well as the interested public, about this significant moment in computing history. The site provides the means to collect and share the memories of those who lived and played their way through this period.

This paper surveys the activity of the Popular Memory Archive over the first eight months of it going live. We reflect on the expectations of the project and discuss the significance of the contributions received online.

The Popular Memory Archive is also conceived as a form of exhibition. It addresses the question by Henry Lowood as to whether videogames are artefacts or activity (Lowood 2004). The site presents the material history of games, their design and their cultures of play. We propose that the Popular Memory Archive's database structure offers the potential to promote more inclusive exhibition practices through its ability to provide new discursive practices online and support multiple narratives. The Popular Memory Archive utilizes some traditional museum components - combining story metaphors with classification and didactics. Its search interfaces, however, allow content to be accessed in more open and non-hierarchical ways. This structure liberates the work from the representation of a singular curatorial interpretation, supporting the contribution of users and allowing for fragmentary and plural interpretations.

\section{The Popular Memory Archive}

The Popular Memory Archive has two main functions:

- To display some of the results of research on local 1980s digital game titles to the wider community in a combined online exhibition and discussion environment. 
- To invite the wider community to contribute their perspectives so that memories, artefacts and information can be collected about this popular medium.

Microcomputer games from the 1980s era - the moment when everyday users first came into contact with computers - hold significant heritage value. Until now, the numbers of digital games held in public Australian and New Zealand collections have been very small. More generally, they have consisted of collections addressing computing's material history.

The 2010 "Preserving Virtual Worlds" report identifies the important work of lay historians and their efforts in building online collections, as well as developing tools for emulation and preservation (McDonough et al. 2010). The report proposes that one of the immediate steps that archives and museums can take to assist in the long term preservation of games is the development of systems that are accessible by, and can accept contributions from, the gaming community. The Popular Memory Archive offers one possible model for documenting the cultural memory around early digital games (Stuckey, Swalwell, and Ndalianis 2013).

\section{HISTORY OF PRODUCTION}

The Popular Memory Archive seeks to balance a history of production in the specific national contexts of 1980s Australia and New Zealand with a history of use and reception. In researching the history of production, we have sought to compile information on as many locally produced 1980s games titles as possible. The Play It Again project has identified more than 900 locally written titles (700+ from Australia and 200+ from New Zealand). From this, we have selected a shortlist of 50 or so titles, which form the online exhibition/ archive.

The Popular Memory Archive database is designed to support a range of perspectives about these games, providing a wide-ranging source 
of information about them. The data is categorized and tagged to cater for different themes to be discovered and appended. For example, pathways following games from a particular year, a person or company, a genre or a platform can be generated (see Figure 1).Structured as a database, the Archive allows visitors to find their own narrative pathways through the information on display. Where exhibitions in the gallery use spatial narratives juxtaposing objects and grouping them to create relationships and generate stories, the online database provides a series of hypertextual possibilities for building meaning.

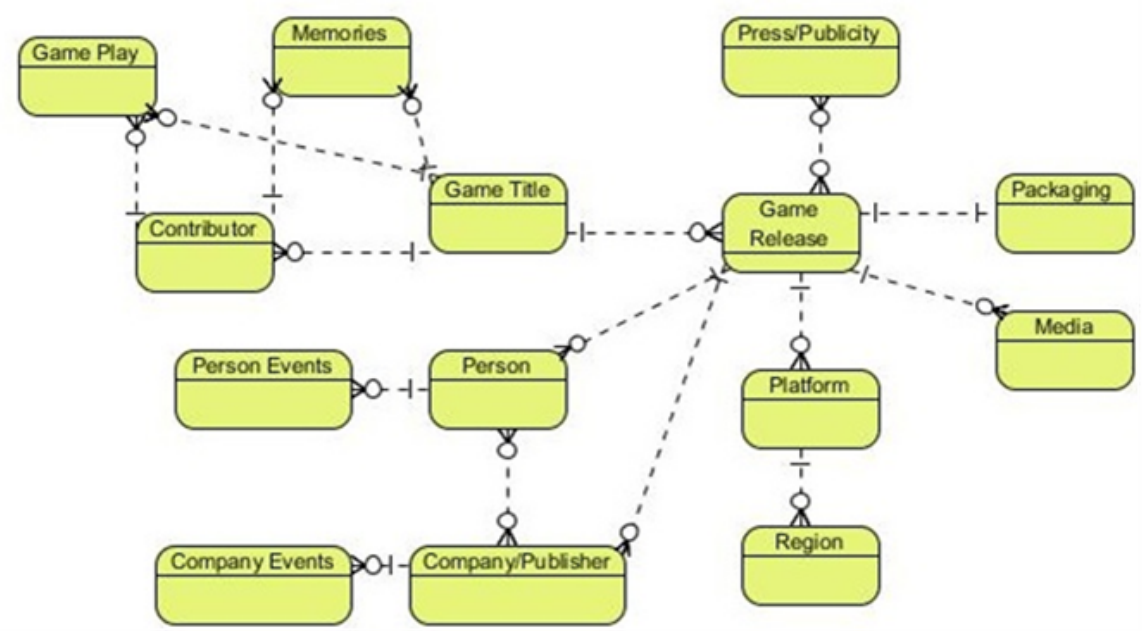

Figure 1: Conceptual Diagram of Popular Memory Archive

Alongside the online exhibition, there is an associated online program of 'events' in the form of a curated blog with a host and guest(s) on monthly themes. Our selection of titles for the shortlist has been conducted with this unfolding public program of guests in mind, to ensure that particular curatorial themes are illustrated. Such themes include: the work of pioneering companies, including Beam Software; the rise of the bedroom coder; local scenes and local themes; legal issues for game archivists; and a focus on the collector. Other criteria informing our shortlist selections are: important game designers; formal innovation/pushing technical limits; popular or 
nationally significant platforms; overall representation and balance; and consideration of the quality of the games. Selections have been based on existing information, interviews and conversations with game designers, as well as systems we already have hard and software for. As much as possible, the project focuses on a breadth and depth of platforms, themes, and contrasting attributes.

The Popular Memory Archive organizes information into conventional searchable categories of classification for games: creators, companies, platforms and dates. The blog posts, however, create additional framing narratives that offer new perspectives to examine the material. The archive also invites visitors to navigate their own way through the collection using searches, tags and keywords.

\section{HISTORY OF CONSUMPTION}

Rather than focused on the evolution of technology the Popular Memory Archive seeks to understand the rise of the microcomputer and the cultural significance of early videogames in terms of a history of use and interaction. This is in keeping with Patricia Galloway's call for the importance of personal knowledge in comprehending personal computing (Galloway 2011). It also echoes the observation Oudshoorn and Pinch make: "Whereas historians and sociologists of technology have chosen technology as their major topic of analysis, those who do cultural and media studies have focused primarily on users and consumers"(Oudshoorn and Pinch 2003). Collections with their object focus have privileged a history of the evolution of technological artefacts, this casts1980s games as archaeological and static objects that exists only in the past, we instead consider that these dynamic forms from the past continue to inflect game culture through memory.

As Joanne Garde-Hansen relates, for thinkers Henri Bergson and Paul Ricoeur "memory, remembering and recording are the key to existence, becoming and belonging”(Garde-Hansen 2011). While their objects of study are different to our own, the intent is similar: 
memory is understood as a collective, social, and oral phenomenon that encourages "a history from below". Arguing a case for “connected memory”, Garde-Hansen recognizes the extent to which our memories are mediated by our media, forming a dynamic relationship that (partially) constitutes our personal and collective identities and what she calls "the construction of our lifeworlds".

Videogames are more than inert, digital code. Games theorist James Newman argues that the act of playing a videogame cannot be adequately considered or appreciated without a deep understanding of the ways in which it is enmeshed within and informed by its cultures and communities, all of whom contribute to the collective knowledge of videogame culture (Newman 2008; Newman 2012).

Recognizing that game culture in the 1980s was highly participatory, hands on, and often characterized by a DIY ethic, the project aspires to create a history of games as they have been used and experienced. We are centrally concerned with making links with a wider audience, connecting historical research into early gaming with those who lived and played their way through this period (as well as those who didn't but are curious). The collation of information about selected game titles is intended to drive the program and act as a prompt to elicit participation and materials from audiences. We want to hear about what people did with early computers and games: what games they played, what games they wrote themselves; what these games mean and meant to them, now and then; what records they have; and what difference their involvement with games made. It is hoped that contributors will add to the knowledge base not only their memories and experiences but also artefacts in need of preservation such as images, videos, documentation, and information about programmers, designers and publishers. For the duration of the Popular Memory Archive's active life (expected to be around 18 months) users can submit comments, images, video and other files to the site. Participation is possible through uploading game capture, screenshots, photos, and the like. 


\section{FAN KNOWLEDGE}

Before examining some of the resources that the Popular Memory Archive has delivered, we need to detour briefly to foreground an earlier (and still on-going) phase of the research, namely our engagement with fan communities (Stuckey and Swalwell 2013). It was fan communities who, years ago, took the initiative to document and preserve historic games long before there was any institutional discussion on their cultural value. Operating outside institutional structures, such groups have been able to advance their work with minimal bureaucracy: they are agile, highly focused on what can be niche-fields of inquiry, and able to draw on the combined knowledge of large communities, and operate along gift economy lines (Baym 1999; Baym and Burnett 2009; Ndalianis 2009; Jenkins 2006; Jenkins 2002). Whilst many have also been involved with creating specialized techniques to help with game preservation, it is the collective intelligence that fans have of games which is of most interest to us in the context of the Popular Memory Archive. Fans have knowledge about the playing of games, the played games and the played with game (Kraus and Donahue 2012; Lowood 2008; Newman 2008; Newman 2011).

The research team, ACMI, and Ngā Taonga recognize that it is the games community that currently holds knowledge about the history of digital games. In considering our approach to exhibiting information about - and seeking to collect documentation of - games, we have looked to the databases created by retro computer game fan sites such as Hall of Light, World of Spectrum and Lemon64. Some of these sites have existed for nearly two decades and have evolved over time, refining their catalogues and the opportunities they present for engagement as the web has grown to support more complex data and more possibilities for participation. Having engaged in this protracted iterative design process, these sites set the standard for how a popular memory archive should function. They have produced archives that strive to address the complex nature of videogames and also reflect how an active user community searches and engages with this material. Sites such as these — built around digitally native 
content by a digitally literate community - can provide memory institutions with a blueprint for what sites seeking to elicit popular memories about games might look like (Stuckey and Swalwell 2013).

\section{CONTRIBUTIONS TO THE POPULAR MEMORY ARCHIVE AND THEIR SIGNIFICANCE}

Fan discourse issues from a situated knowledge that is based on lived experience. Fans and players typically understand games as a set of experiences. Gamers - sometimes motivated by nostalgia and by a personal past with the software and hardware - often frame games in an intimate dialogue. This information provides insight and understanding about historic games that cannot be communicated from experiencing the games themselves.

For example the comments that we have received on the Popular Memory Archive in response to a blog post on the memorable loading scream from Beam Software's The Way of the Exploding Fist (Beam Software, 1985) focus not just on the game itself, but where people played it, who they played with, and even how they played with the game.

Stu232 recalls the shock of the loading scream and how he took advantage of the killer leg swipe move which, once mastered, gave the player a noted advantage in what was otherwise a very challenging game. His comment is a knowing wink to those players who used this exploit to play through the game.

“Looks like I'm not the only one to have been caught out by that fecking scream during the load! <smile>

My mate told me to sit close to the TV (apparently the manual advised this - according to my lying friend). I was sipping a glass of cola and all of a sudden that SCREAAAAAAAAAM happened and my cola went everywhere. $<$ smile> 
Absolutely loved the game, I was the master of sitting on my bum and leg swiping everyone that came close <wink>”

Whilst the scream is not actually part of the gameplay, it is in people's memories a defining part of the game. Dave Farquar's introduction to the game was at a friend's house where he learnt more than just gameplay tricks. His comment also remind us how early tape games were commonly copied and shared amongst friends. He writes:

"I remember that scream too. - I got my introduction to the game in 1988 or so. I was at my best friend's house, and he said, "Watch this," then cranked the volume at just the right time and freaked his younger sister out with that sound effect. So of course I asked for a copy, took it home, and did the same thing to my younger sister. Ah, youth.”

Beam Software were one of the earliest companies to create a fast loader - the 'Pavaloada' - and devise a way to add sound and animation to the tape load sequence. Whilst to audiences today The Way of the Exploding Fist's tape loading scream might appear inconsequential, it was momentous in its day. It can be difficult to appreciate the innovation and achievements of early video games as rapid technological change renders the most sophisticated features of 1980s games crude to contemporary audiences. As the 2010 “Preserving Virtual Worlds Report” notes, context is critical for creating an understanding of games for future users and researchers (McDonough et al. 2010). An understanding of both the social and material conditions of the consumption and reception of these early games is difficult to collect, preserve and display. Comments such as those of Farquar and Stu232 communicate something of the context in which gameplay took place. Documenting player memories is one way to approach this issue and to record the experience of these games beyond the screen.

\section{Uploads}

We are collecting images of people playing computers from the era. 
Like the comments on Way of the Exploding Fist, such images provide context as to how people played games in this era. One black and white image contributed by Jenny Scott shows a grandfather and grandchild silhouetted and concentrating on playing an unidentified early version of 'tennis' on a small television in 1981. Pictured in a living room, it shows the surrounds in which domestic gameplay took place in this era. A later image also contributed by Jenny Scott shows her daughter, Katie, sitting in a lounge chair with a joystick playing a space shooter (probably a Gyuss clone?) on a Commodore 64 (see Figure 2). The Commodore 64 has both a tape and disc drive. It is set up on a side table and appears as an ad hoc intervention in the space. Alan Laughton has shared an image of him and his young daughter playing on a Tandy CoCo (TRS-80 Colour Computer) lent to him at Christmas 1984/85. They too are in the living room and the computer is propped up on a fruit box connected to the family TV. Toys are scattered around the floor and the computer blends into the landscape of family entertainment. In comparison, Kevin Phillips' photo from 1989 shows his workstation with his faithful ZX Spectrum, 14" Kambrook TV set and National cassette recorder set up on a kitset computer desk. It illustrates a time when the home computer was not only becoming a more familiar part of the furniture, finding its way into teenagers' bedrooms and even dedicated computer rooms, but furniture was being designed especially for it. 


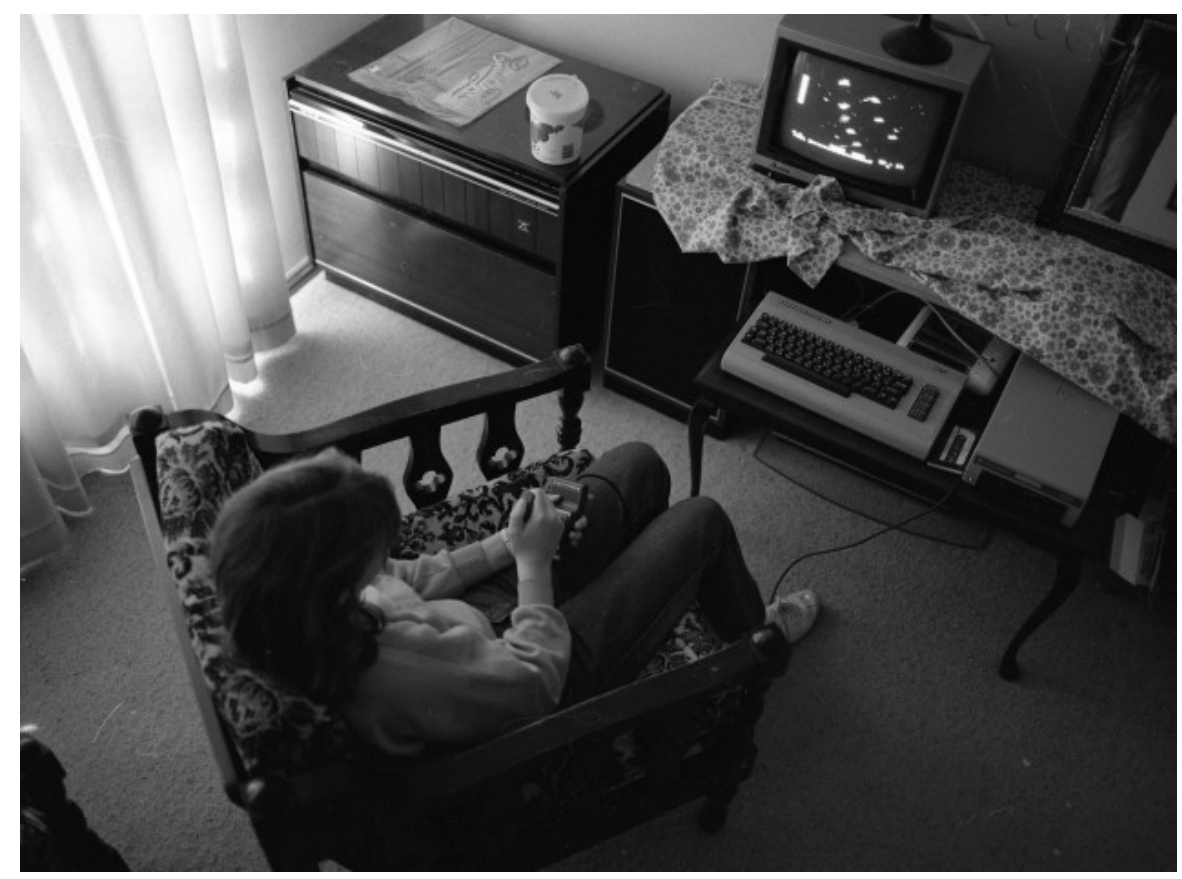

Figure 2: Katie Scott, playing on a Commodore 64 purchased Christmas 1985.

The archive documents a time when computer games were emerging as distinct cultural artefacts from within the burgeoning culture of home computing. In the early 1980s computer games were not well established as commercial products and users of personal computers mostly got their games from typing in listing from magazines or swapping them at software meet-ups. New Zealander Kevin Philips recounts how his first foray into programming was via the book 34 Amazing Games for the $1 \mathrm{~K} Z \mathrm{ZX81}$. His post includes images of the book featuring games like "Golf" and "Along the Wire" that have about 16 lines of code to enter. His next post offers game capture of a collection of ZX Spectrum games that he discovered on an old cassette and got working again under emulation (see Figure 3). These were games he had typed in from magazines in the 1980s, as he explains:

“That's pretty much where and how I think many people 
(including myself) built their skills in games programming. I recall getting new magazines each week, sitting at home and typing in loooong listings of games to play. Sometimes they were awful, sometimes they were pretty cool... If it was a great game, it got saved. These days, its funny to think how much time I'd spend typing in a game to just type "NEW" and start a new one... Without saving....”

These early games are missing from most histories of videogames as they are frequently authorless, often copies of arcade games and not valued as design (Swalwell 2008). They were, however, many people's first encounter with both games and computing.

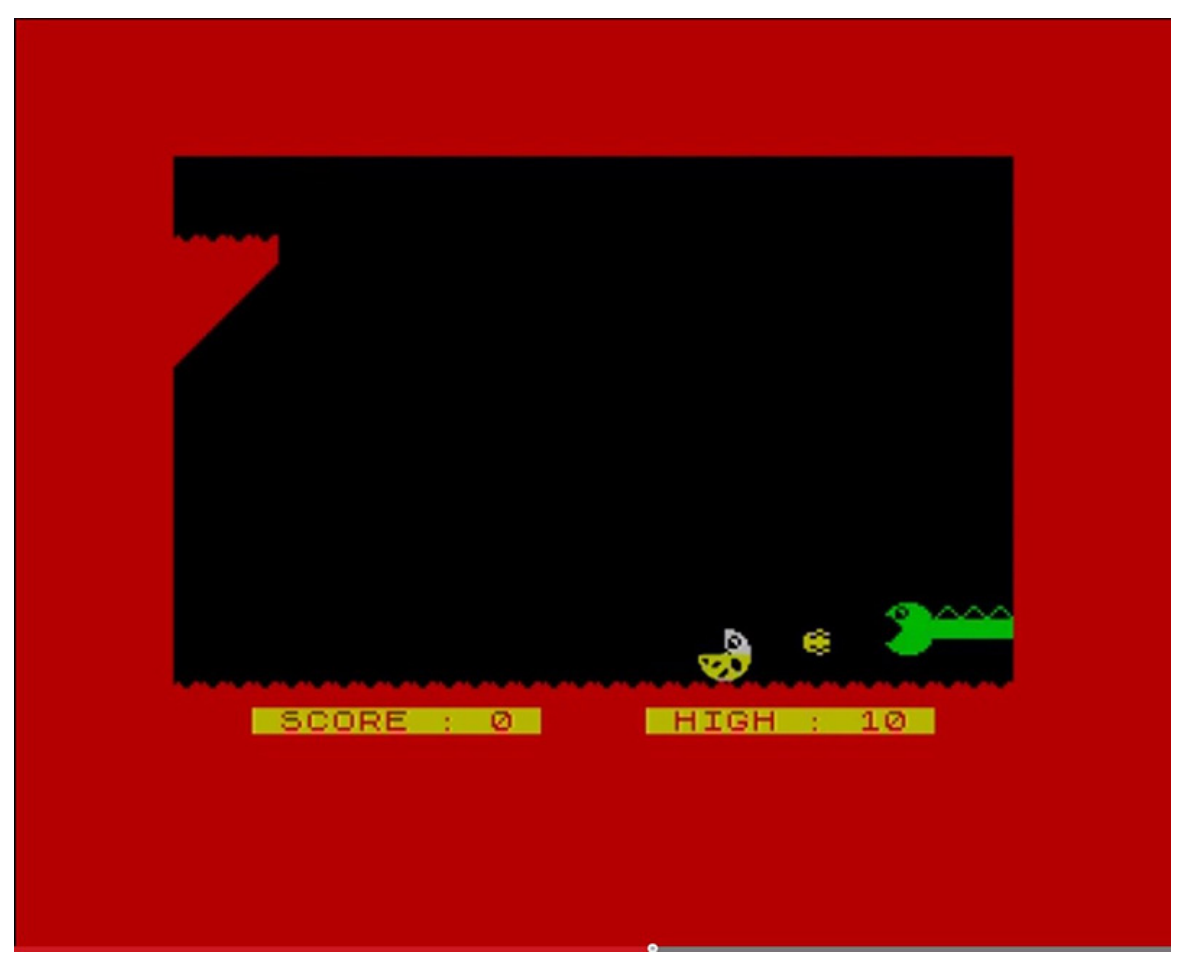

Figure 3: Typed in games of the 1980s - ZX Caveman 
Philips wrote a lot of games in the 1980s, but he was not a commercial developer. He describes them as something to do on the microcomputer, "write games, play games and make pictures in Melbourne Draw". Some of his work has survived on cassettes and others as printed out code listings. Many were 'clones' such as his Mine Sweeper game. Others were inspired by games he had enjoyed. Gemrun (1987) is based on the popular Boulder Dash (First Star Software, 1984). Not only has Philips made his old games available to download through links accessible from the Play it Again site, he has also shared a design document he created for a clone of the arcade game Centipede (Atari, 1981). This document illustrates his process of first working out his ideas on paper, including checking all the calculations before beginning to code. His old design notebooks record his techniques for addressing recurrent design issues, such as pre-shifting sprites, collision detection and other challenges on the ZX Spectrum (see Figure 4).

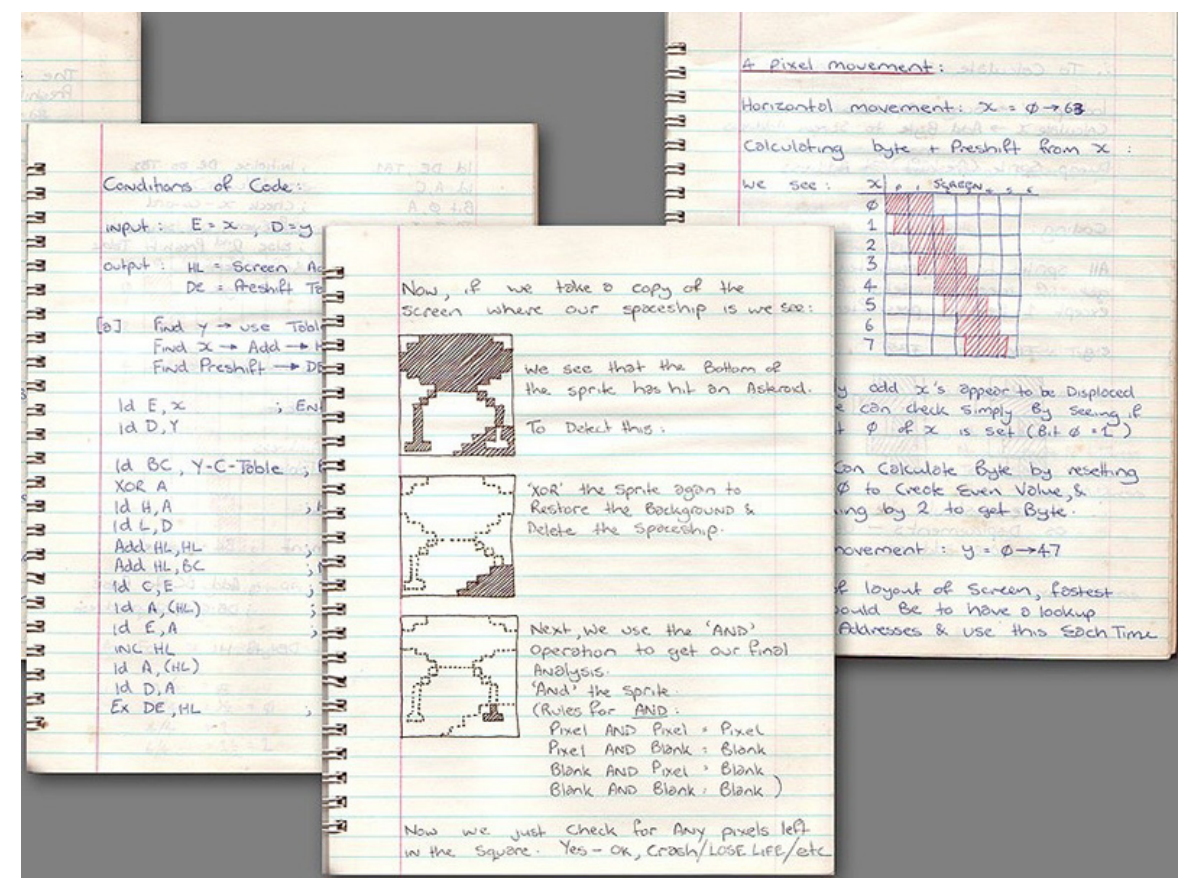

Figure 4: Kevin Philips’ Sprite Algorithms notebooks 
Game designers have also contributed their recollections of the era, including Veronika Megler, one of Beam Software's earliest employees and co-designer of Melbourne House's huge hit, the graphic text adventure The Hobbit (1982). Having left Beam after completing the game in 1982, she describes her astonishment at discovering the impact the game had on players in the 1980s, recounting stories from her encounters with fans who have tracked her down to share their memories.

Professional Australian game developers John Passfield (Interactive Binary Illusions, Krome, Pandemic, Right Pedal Studios), Matthew Hall (KlickTock, Hispster Whale), and New Zealander Carl Muller (who has worked at large international developers including Probe Software and Jakks Pacific) discuss how they got started designing games back in the 1980s, as home coders. Muller and Hall reveal the importance of how-to-books for their formative game design experiments. Muller and Passfield share tales of selling their early designs. Muller recounts how he typed one of his designs into the display computer at a local shop, as his own system did not have enough RAM to run it, and the shop owner sold a copy of the game then and there to a keen customer. The schoolboy Passfield published his game Chilly Willy (1984) - a Pengo clone - through Honeysoft, but never told his friends at school as he thought it would seem too 'nerdy'. In the comments to Passfield's blog, 'Leon' shares that whilst he also published his games in this era, like Passfield he hid his hobby from his school friends.

These conversations between early designers and others in the community have served both as a form of fact checking, and to unearth more information. For instance, Leon offered a correction to the RAM size of the VZ200, the Dick Smith computer that Passfield mentioned in his text. Meanwhile, New Zealand game designer, Mark Sibly (of Blitz fame), alerted us to the fact that the gameplay video posted on the site was not actually of 'his' Dinky Kong (1984), but of a game of the same name from the era (his was for the Vic 20, not the Oric). This is a common issue confronting game historians, particularly working with games that are clones or homages to other 
games. From this exchange, we were able to not only correct this error, but also identify a number of Sibly's other games.

A very pleasing outcome of the kind of knowledge and skill sharing made possible through the portal concerns Alan Laughton's involvement from the Microbee Software Preservation Project. Laughton accepted the challenge of converting a listing of a game written by Australian designer Matthew Hall (Hipster Whale). Created on his primary school's Microbee, Matthew Hall's text adventure Jewels of Sancara Island (1988) had survived the last thirty or so years as a Turbo Pascal listing (see Figure 5). Finding the game listing on the Popular Memory Archive, Laughton OCRed it, correcting errors that crept in before compiling it for the Microbee. The game can now be downloaded and played.

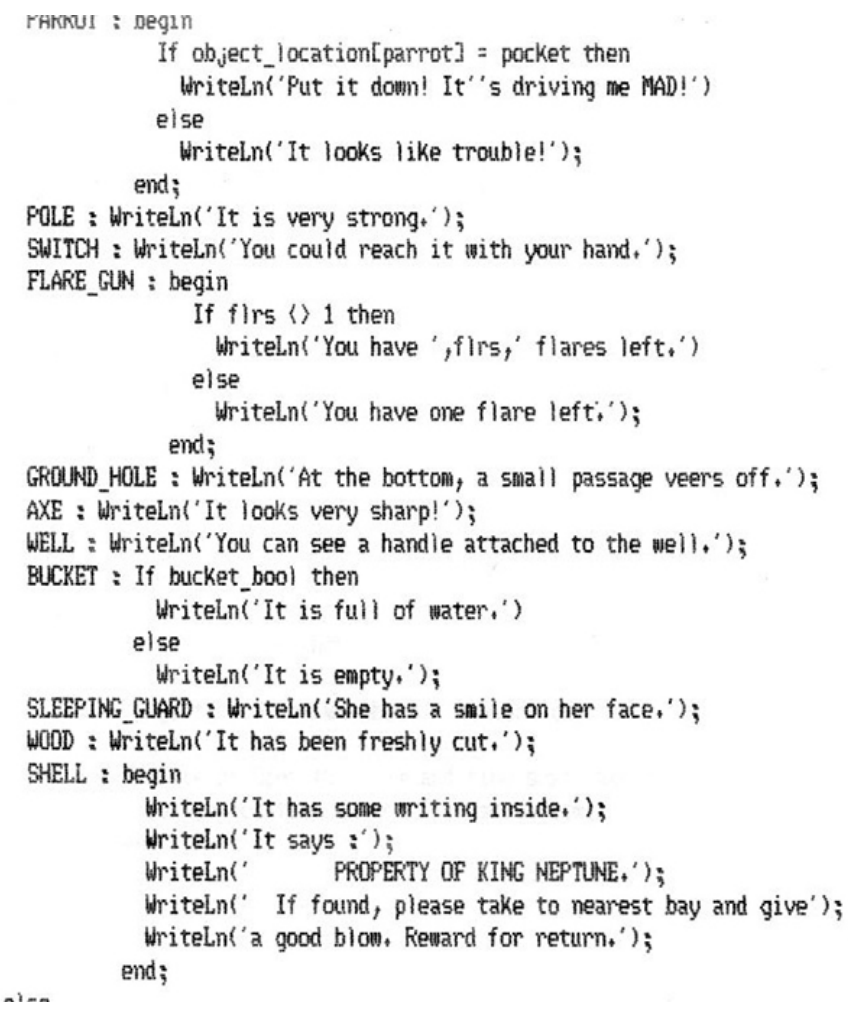

Figure 5: Matthew Hall, Jewels on Sancara, Turbo Pascal listing, detail from Commands 5 


\section{Local Histories of Technology}

Whilst there is a growing body of material on the history of games, this has most often been centred on the United States, Japan and more recently the United Kingdom. There is a paucity of scholarly and collection information on the history of games from the 'periphery'. It is the focus of only a few historico-cultural studies. These include work on Finland, the former Czechoslovakia, and New Zealand (Saarikoski and Suominen 2009; Saarikoski 2003; Suominen 2011; Svelch 2011; Swalwell 2007; Swalwell 2009; Swalwell and Davidson). In her work on the early history of New Zealand games, Swalwell advocates the need to pay attention to local specificities and anomalies in the stories of games production and how these points of difference reveal that the historiography of technology, whilst in part global, is also culturally specific (Swalwell and Davidson).

As our project is focused on Australian and New Zealand games, we are in part shaping conversations as local, by virtue of the games we have selected and the guests we are featuring. Examples of specifically local stories include responses to a post on Microbee user groups. The Microbee was a microcomputer (originally a kit computer) that was designed and produced in Australia. Cheap and affordable it was adopted by several Australian State Education Departments for computing in schools.[1] These user group memories include the all-important software-swap and programming assistance that - in an era of little commercial software and support - was the bedrock of user meetings. Laughton recalls that the Melbourne Microbee Users Group (MBUG) had a library of 186 discs of Public Domain software, an invaluable source of generic and locally-written software for users.

Education games present another part of the local story. Pieces of Eight (1986) - an educational graphic text adventure for the Apple II, Commodore 64 and TRS80 - was played in schools across Australia and offered many young Aussies their first encounter with the computer. Pieces of Eight presented such a fun and engaging experience it launched a thousand gamers, many of whom have since 
trawled retrogamer sites looking for information on this title, unaware that it was in fact produced by the Queensland Department of Education. 'DG' recalls on the Popular Memory Archive how Jacaranda Software's Goldfields (1986) game - where you play a new arrival keen to make their fortune in the gold-rush era - "was a beloved part of the history classes for year 4 and 5 students" at St Joseph's College, Nudgee in the early 1990s. Educational titles such as Goldfields also came with extensive teacher notes and classroom kits, which valuably document suggested methods of incorporating games into the curriculum. Despite their reach and impact, these early educational titles have, to date, been left out of more established game histories.

We are not pursuing the local to the exclusion of the non-local, however, and oftentimes the local and global histories overlap, such as the way that the vagaries of international publishing law informed and underpinned the creation of Melbourne House, an Australian publisher with a U.K. identity. It is no exaggeration to say that Melbourne House, with their Australian-based development studio, Beam Software, were significant players in the U.K. games publishing scene of the 1980s. Meanwhile, a Dunedin-based duo, Andrew Bradfield and Harvey Kong Tin, spent years writing their two games for the Atari computer, Laser Hawk (1986) and Hawkquest (1989), and these had commercial releases through the U.K. publisher, Red Rat. Finally, we are also attentive to the ways in which imported titles and products such as gaming magazines helped to shape local gaming cultures.

\section{ONLINE AUDIENCES}

For some years, museums have been inquiring into how Web 2.0 can be used effectively to provide access to, and engagement with, collections. Much of the discussion has been about trying to excite and engage online audiences by offering access to digital images of collection objects and working with social networks on Facebook and blogs (Russo et al. 2008; Simon 2007; Carreras and Mancini 2010; Kelly 2010). Some museums have experimented with engaging 
gamer communities online. In the lead up to their 2012 exhibition The Art of Videogames, the Smithsonian invited online audiences to partake in the curatorial process by nominating their preferred games from existing short-lists. The Smithsonian curatorial team prepared the lists of games and organised them by platform and genre. It was an inspired marketing move that reached out to core audiences and told them that their knowledge and opinions were important to the cultural institution. It was, however, structured in a way that constrained the curatorial narrative. Perhaps aware of how partisan games audiences can be, the lists were already dominated by the 'usual suspects' and the act of curation by popular vote ensured that the final selection included no surprises or allowed for more deeply considered examinations. It was an exercise in reductive classification, shutting down possibilities for meaning. Its focus on the evolution of graphics and gaming systems championed the dominant narrative of technological advancement, sacrificing more critical narratives about the creation and reception of videogames.

The 100 Toys project at the Indianapolis Museum of Childhood offers a more considered example of the Museum working with online audiences on questions of play. They asked online audiences to vote on the toys that defined childhood, from a selection of 100 in their collection. Voters were also asked to share their memories of playing with the toys, thus contributing knowledge directly to the collection. The museum received 24,000 votes and 600 stories on their online portal. They then used this information to provoke discussion, such as comparing the curator's top 20 list to the crowd-sourced list. There was a $70 \%$ overlap between the curator's choice and the crowd's. This observation served to make the six different toys on each list a focus for numerous interesting questions.

The online space offers new opportunities for the Museum to engage with its audiences. In 2001, Patterson Sims noted that the Museum of Modern Art (MoMA) receives more visits to their site than their building. Sims proposed that the web acts not as "a lure for the museum" but rather exists as a parallel museum.[2] A recent “curatorial experiment” exploring this concept is MoMA's Design 
and Violence exhibition (2013-ongoing). It interrogates the polite assumption that good design is benign and aesthetically pleasing, one that curator Paola Antonelli finds the museum guilty of perpetuating (Burke 2013). The exclusively online exhibition is discursive in structure, organised as a series of posts, each of which focuses on a piece of design. Each object is presented with a short essay by an invited expert whose text concludes with a question that invites response. The resultant discussions by visitors form part of the exhibition, presenting contested understandings of both the object and the concepts discussed.

Curators Antonelli and Hunt argue that they wanted to publish online rather than show in the gallery because they wanted a dialogue with the public. Envisaging exhibition as a conversation - an exchange of information where the museum can learn - also freed them to address work that is not owned by MoMA and work that cannot be collected and displayed in a conventional sense, from cattle runs for slaughterhouses to prison panopticons.[3] Whilst Design and Violence has a strong curatorial narrative, it is not didactic but inclusive in its approach (Antonelli 2013).

The promotion of more inclusive practices is celebrated by Fiona Cameron and Helena Robinson in their examination of museums providing online access to searchable collection databases (Cameron and Robinson 2010). They argue that "Museums must devise a way in which the need to provide expert and scholarly information can co-exist with an acknowledgment of the fragmentary, arbitrary, and plural nature of object interpretation” (Cameron and Robinson 2010 p172). In their analysis, they argue that digital database construction and digital narratives can work together to enable users to link information in ways not previously possible. Databases allow for museum 'objects' to be interrupted in a variety of ways, emancipated from narrow and exclusive cultural, disciplinary and museum-based understandings from curatorial specialty areas. Whilst their research accepts that audiences need the Museum to provide some structure and scholarly interpretation, they argue that users desire to work with more fluid and malleable structures and information retrieval 
tools, which can facilitate the creation of multiple narratives around collections.

\section{SIGNIFICANCE FOR THE MUSEUM}

The Museum of the 21st century has shifted from an object focus to one of access and experience (MacDonald and Alsford 2010). As videogames are defined by their promise of interactivity, it is tempting to assume that they will simply offer themselves up as an experience in the gallery. Observations by games theorist and academic Brendan Keogh suggest that it is not so straightforward. He recalls his initial excitement at the chance to play System Shock (Looking Glass Studios 1994) at the ACMI Game Masters exhibition in 2012, quoting designer Warren Spector's amazement at seeing the working game in the gallery when the "devs" themselves struggle to get it running. On reflection, Keogh finds playing System Shock in the gallery less than edifying. The game reveals little about itself in the short game time possible in the gallery. He finds it hard to see past the "obscure old controls" let alone determine what makes the game culturally significant (Keogh 2012). In the exhibition, the game, whilst narratively contextualised within Spector's career, is basically presented like a work of art, left to reveal its inherent value through audience engagement, rather than have its story told through associated documentation and display. Keogh's admission is a reminder of how mute games can be in the gallery, and how quickly objects of technology become estranged when they are divorced from their original social and cultural conditions of use (Gitelman 2006).

\section{Moving Beyond the Object Focus}

Operating online, the Popular Memory Archive already entails a shift beyond the Museum's historic object focus. The hypertexual nature of the database also means that games are located within multiple narrative readings. For example, Beam Software's The Hobbit can be contextualized through a multitude of associations: Beam's other games; text adventures; the platforms it played on; adventure clubs; games made in 1982 as well as the specific stories of its production 
and reception. These 'stories' are presented in a variety of voices from the scholarly, to the designers, and fans. These voices have different tones, to pick up on an earlier point about fans' passion, passionate voices are engaging in a way that the measured tones of the Museum are not. In examining the effects of "Discussion Exhibitions” at the London Science Museum, Ben Gammon and Xerxes Mazda note that one of the motivations for visitors to read the comments of others is that the emotive language of visitor's comments is more compelling than display didactics (Gammon and Mazda 2009). The passion of the retro gamer and fan captures a sense of the lived experience and its importance to the user. Oral histories, even fragments thereof, provide a nuanced and embodied relationship with the work.

\section{CONCLUSION}

Games exist as both text and performance. James Newman has argued for the centrality of play in preservation, arguing that the discipline of Game Studies has established that games come into being though the act of play.[4] In this article, we've focused on player memory as a valuable resource, but we are also committed to making it possible for users to play historic games. It need not be an either/or thing.

The next step for the Popular Memory Archive is to incorporate versions of games to play in the browser. This creates challenges, both technical and legal (in April 2014 the Archive's curated blog addressed copyright issues for orphaned and abandoned works). We also recognise that some game aficionados are extraordinarily committed to the gaming experiences they have had in the past, to the extent that their motivations and concerns may not sit easily with the more critical concerns of game historians and curators. Swalwell has written of some "game lovers"” refusals to recognise the realities of needing to display games in ways that differ from their original presentation. Some consider any departures 'inauthentic', a position that she argues is based upon the common sense notion that history is about 'the way it really was'. Critical scholarship will sometimes 
come up against those who adamantly continue to privilege the ‘original experience' above all else (Swalwell 2013).

Nevertheless, situated amongst stories of its production, reception and the culture of the era - yet divorced from its historic hardware - our rationale is that playable games located within the Popular Memory Archive's web of information might offer more meaningful play experiences than in the gallery. Online, the emulated games will be liberated from their status as museum 'objects'. Audiences should not expect them to offer identical experiences to those they presented in the 1980s. Rather they become part of what net.art preservationist Anne Laforet would describe as an archaeological assembly of fragments helping audiences to imagine a "plausible state of what the original situation could have been” (Laforet 2007). The Popular Memory Archive presents how an online exhibition/ collection might blend the voices of game designers, players and retro-computing hobbyists with those of the historian and museum professional to produce a richer understanding of videogames from this era in computer culture.

\section{ACKNOWLEDGMENTS}

This research is supported under the Australian Research Councils Linkage Projects funding Scheme (project numbVer LP120100218).

Earlier versions of this paper have appeared in: Stuckey H, Swalwell $\mathrm{M}$ and Ndalianis A, "The Popular Memory Archive: Collecting and Exhibiting Player Culture from the 1980s" in Arthur Tatnall (ed), Making the History of Computing Relevant (IFIP Springer 2013), and Stuckey, Helen, Melanie Swalwell, Angela Ndalianis, Denise de Vries (2013) "Remembrance of Games Past: The Popular Memory Archive”, 9th Australasian Interactive Entertainment Conference proceedings, ACM Digital Library, http://dl.acm.org/ citation.cfm?id=25135.

\section{ENDNOTES}

[1] The Microbee made its debut as a kit computer in 1982 and after 
winning a tender from the New South Wales Education department quickly graduated to a prebuilt version. Its last model, the Matilda, ceased production in 1990. In 2012 Microbee re-released a limited edition version of their original kit computer.

[2] Quoted in Graham and Cook p.179 (Graham and Cook 2012)

[3] The site also allows them to show work that does not sit comfortably with MoMA's collection policy and governance. Antonelli has previously spoken about MoMA's refusal to let her collect a Beretta semi-automatic pistol for the Design Collection and its concern about collecting violent videogames. (Antonelli 2013)

[4] Newman asserts that some of the materials that we might ordinarily think of as being part of the contextualising ephemera that situate the original game, may be potentially capable of telling the story better than the game itself, in particular walkthroughs and strategy guides.

\section{Bibliography}

Antonelli, P. "Paola Antonelli: Why I Brought Pac-Man to MoMA." In TED Salon NY2013. Accessed August 1, 2015. http://www.ted.com/talks/ paola_antonelli_why_i_brought_pacman_to_moma.html, 2013.

Baym, N. Tune In, Log On: Soaps, Fandom and Online Community. Thousand Oaks, CA: SAGE, 1999.

Baym, N. and R. Burnett. "Amateur Experts: International Fan Labour in Swedish Independent Music.” International Journal of Cultural Studies vol. 12, no. 5, 2009: 433-449.

Beam Software. The Way of the Exploding Fist. [Commodore 64]. Melbourne House, 1985.

Burke, A. "Paola Antonelli Interview: 'Design Has Been Misconstrued as Decoration.” The Conversation. 
http://theconversation.com/paola-antonelli-interview-design-hasbeen-misconstrued-as-decoration-21148, 2013.

Cameron, F. and H. Robinson. "Digital Knowledgescapes: Cultural, Theoretical, Practical and Usage Issues Facing Museum Collection Databases in a Digital Epoch.” In Theorizing Digital Cultural Heritage, edited by F. Cameron and S. Kenderine, pp. 165-191. Cambridge, MA.: MIT Press, 2010.

Carreras, C. and F. Mancini. "Techno-Society at the Service of Memory Institutions: Web 2.0 in Museums." Catalan Journal of Communication Cultural Studies vol. 2, no. 1, 2010: 59-76.

Galloway, P. "Personal Computers, Microhistory, and Shared Authority: Documenting the Inventor-Early Adopter Dialectic.” IEEE Annals of the History of Computing vol. 33, no. 2, 2011: 60-74.

Gammon, B. and X. Mazda. "The Power of the Pencil Renegotiating the Museum Visitor Relationship.” Exhibitionist, 2009: 26-33.

Garde-Hansen, J. Media and Memory. Edinburgh: Edinburgh University Press, 2011.

Gitelman, L. Always Already New: Media, History, and the Data of Culture. Cambridge, MA.: MIT Press, 2006.

Graham, B. and S. Cook. Rethinking Curating: Art after New Media. Cambridge, MA.: MIT Press, 2012.

Jenkins, H. "Interactive Audiences? The 'Collective Intelligence' of Media Fans.” In The New Media Book, edited by D. Harries, pp. 134-151. London: British Film Institute, 2002.

Jenkins, H. Fans, Bloggers, and Gamers: Exploring Participatory Culture. New York: New York University Press, 2006.

Kelly, L. "How Web 2.0 is Changing the Nature of Museum Work." Curator Museum Journal vol. 53, no. 4, 2010: 405-410. 
Keogh, B. "Mastering Game Exhibits." Unwinnable: Life with Culture. http://www.unwinnable.com/2012/07/10/mastering-gameexhibits/\#.U5U12vmSx8E, 2012.

Kraus, K. and R. Donahue. “'Do You Want to Save Your Progress ?’: The Role of Professional and Player Communities in Preserving Virtual Worlds Risks to Videogame Longevity.” Digital Humanities Quarterly vol. 6, no. 2, 2012: 1-18.

Laforet, A. "Preservation for Net Art in Museums.” In Digital Visual Culture: Theory and Practice, edited by A. Bentkowska-Kafel, T. Cashen and H. Gardiner, pp. 109-118. Bristol: Intellect Books, 2007.

Lowood, H. "Playing History with Games: Steps towards Historical Archives of Computer Gaming." Presented at The Annual Meeting of the American Institute for Conservation of Historic and Artistic Works, pp. 1-13. Portland, Oregon. http://cool.conservation-us.org/ coolaic/sg/emg/library/pdf/lowood/Lowood-EMG2004.pdf, 2004.

Lowood, H. "Found Technology: Players as Innovators in the Making of Machinima." In Digital Youth, Innovation and the Unexpected, edited by T. McPherson, pp. 165-196. Cambridge, MA.: MIT Press. 2008.

MacDonald, G.F. and S. Alsford. "The Museum as Information Utility.” In Museums in a Digital Age, edited by Ross Parry, pp. 72-79. Oxon: Routledge, 2010.

McDonough, J. P., R. Olendorf, M. Kirschenbaum, K. Kraus, D. Reside, R. Donahue, A. Phelps, C. Egert, H. Lowood and S. Rojo. "Preserving Virtual Worlds Final Report." https://www.ideals.illinois.edu/handle/2142/17097, 2010.

Ndalianis, A. "Chasing the White Rabbit to Find a White Polar Bear: Lost in Television.” In ReadingLost: Perspectives On A Hit Television Show, edited by R. Pearson, pp. 193-310. London: I.B.Tauris, 2009. 
Newman, J. Playing with Videogames. Convergence. New York: Routledge, 2008.

Newman, J. “(Not) Playing Games: Player-Produced Walkthroughs as Archival Documents of Digital Gameplay.” International Journal of Digital Curation vol. 6, no. 2, 2011: 109-127.

Newman, J. Best Before: Videogames, Supersession and Obsolescence. London: Routledge, 2012.

Oudshoorn, N. and T. Pinch. "Introduction: How Users and NonUsers Matter." In How Users Matter The CoConstruction of Users and Technology, edited by N. Oudshoorn and T. Pinch, pp. 1-25. Cambridge, MA.: MIT Press, 2003.

Russo, A., J. Watkins, L. Kelly and S. Chan. 2008. "Participatory Communication with Social Media." Curator The Museum Journal vol. 51, no. 1, 2008: 21-32.

Saarikoski, P. "Club Activity in the Early Phases of Microcomputing in Finland.” In History of Nordic Computing, edited by J. Bubenko, J. Impagliazoo and A. Solvberg, pp. 277-287. New York: Springer, 2003.

Saarikoski, P. and J. Suominen. "Computer Hobbyists and the Gaming Industry in Finland." IEEE Annals of the History of Computing vol. 31, no. 3, 2009: 20-33.

Simon, N. "Discourse in the Blogosphere.” Museums Social Issues 2, no. 2, 2007: 257-274.

Stuckey, H. and M. Swalwell. 2013. "Retro-Computing Community Sites and the Museum.” In The Handbook of Digital Games, edited by H. Agius and M. Angelides, pp. 523-547. Hoboken, NJ.: John Wiley \& Sons, Inc, 2013.

Stuckey, H., M. Swalwell and A. Ndalianis. "The Popular Memory Archive: Collecting and Exhibiting Player Culture from the 1980s.” 
In Making the History of Computing Relevant, edited by A. Tatnall, pp. 215-225. Berlin: IFIP Springer, 2013.

Suominen, J. "Retrogaming Community Memory and Discourses of Digital History.” In Navigating Landscapes of Mediated Memory, edited by P. Wilson and P. McEntaggart. Inter-Disiplinary Press, 2011.

Svelch, J. "Indiana Jones Fights the Communist Police: Text Adventures as a Transitional Media Form in the 1980s Czechoslovakia.” Paper presented at Media in Transition 7. Cambridge, MA., 2011.

Swalwell, M. “The Remembering and the Forgetting of Early Digital Games: From Novelty to Detritus and Back Again.” Journal of Visual Culture vol. 6, no. 2, 2007: 255-273.

Swalwell, M. "1980s Home Coding: The Art of Amateur Programming.” In The Aotearoa Digital Arts Reader, edited by S. Brennan and S. Ballard, pp. 193-201. Auckland: Aotearoa Digital Arts \& Cloud, 2008.

Swalwell, M. "Towards the Preservation of Local Computer Game Software: Challenges, Strategies, Reflections." Convergence: The International Journal of Research into New Media Technologies vol. 15, no. 3, 2009: 263-279.

Swalwell, M. 2013. "Moving on from the Original Experience: Games History, Preservation and Presentation.” In Proceedings of DIGRA 2013: Defragging Games Studies., Altanta, USA. http://www.digra.org/wp-content/uploads/digital-library/ paper_454.pdf

Swalwell, M. and M. Davidson. "Game History and the Case of 'Malzak': Theorizing the Manufacture of 'local Product' in 1980s New Zealand.” In Locating Emerging Media, edited by G. Halegou and B. Aslinger. New York \& London: Routledge, 2015. 